\title{
Lipid content of malignant lymphomas
}

\author{
D. H. WRIGHT ${ }^{1}$ \\ From Makerere University College Medical School, Kampala, Uganda
}

SYNOPSIS Lipid staining, using oil red 0 and Sudan black B stain, was carried out on frozen sections of formalin-fixed tumour tissue from 142 cases of malignant lymphoma. Most cases of Burkitt's tumour contained abundant coarse lipid droplets both within the cytoplasm of the lymphoid cells and within non-neoplastic histiocytes scattered throughout the tumour. Lymphocytic lymphomas contained little stainable fat. Histiocytic and stem-cell lymphomas were almost equally divided between those containing abundant lipid droplets and those devoid of lipid. It is suggested that the demonstration of abundant cytoplasmic lipid droplets may assist in the diagnosis of Burkitt's tumour although this feature is not in itself diagnostic. The significance of the lipid droplets in the cells of Burkitt's tumour is discussed in relation to the histogenesis of the tumour.

The differentiation of malignant lymphomas on the basis of histological preparations alone can be difficult and is very dependent on the quality of fixation and processing of the tissue. Imprint cytology is an excellent technique for demonstrating cytological detail and is a valuable adjunct to the histological method in the diagnosis of malignant lymphomas. Unfortunately it is not always possible to obtain imprint cytology, particularly in central laboratories serving outlying hospitals in which the tissue is of necessity received in a fixed state. Under these circumstances interpretation of cytological features in histological sections may be of diagnostic value. Thus, Wright and McAlpine (1966) noted that the intense cytoplasmic basophilia of Burkitt tumour cells in Romanowsky-stained imprint preparations corresponded to marked cytoplasmic pyroninophilia in tissue sections and recorded the value of this feature in the diagnosis of Burkitt's tumour. In imprint preparations cytoplasmic vacuoles, corresponding to neutral fat droplets, are a characteristic feature of the majority of Burkitt tumour cells (Wright, 1963) (Fig. 1), whereas they are uncommon in most lymphocytic lymphomas (Fig. 2) and of variable prominence in histiocytic and stem-cell lymphomas (Figs. 3 and 4). The purpose of this investigation was to see whether these lipid droplets could be demonstrated in sections of formalin-fixed tissue, and if so, whether their presence aided in the diagnosis of Burkitt's tumour and its separation from other types of malignant lymphoma.

'Present address: Department of Pathology, University of Birmingham Medical School, Birmingham 15

Roceived for publication 8 February 1968.

\section{MATERIALS AND METHODS}

The biopsies included in this study were received from various hospitals in Uganda for routine diagnostic histology. All cases of malignant lymphoma received during 1966 and 1967 were included provided that an adequate quantity of tissue remained after the blocks for histology had been taken. This series does not, therefore, include all cases of malignant lymphoma seen during this period and is to some extent biased to include larger biopsies. Tissues from nine cases of malignant lymphoma coming to necropsy at Mulago Hospital were also included, giving a final total of 142 cases.

A division of the cases into four categories-Burkitt's tumour, lymphocytic lymphoma, histiocytic and stemcell lymphoma, and Hodgkin's disease-was made on the basis of histology alone. The criteria used for the diagnosis of Burkitt's tumour have been described by Wright (1967). In presenting the results, well differentiated and poorly differentiated lymphocytic lymphomas have been grouped together because of the small number of cases. Similarly, histiocytic and stem-cell lymphomas have been grouped together partly because many pathologists group these tumours together as reticulum cell sarcomas and also because the point at which a division is drawn between a poorly differentiated histiocytic lymphoma and a stem-cell lymphoma is to some extent arbitrary. All cases of Hodgkin's disease have been placed under one heading, the assessment of lipid content being made on Sternberg Reed cells and malignant histiocytes only.

All of the biopsies were fixed in $10 \%$ formol saline for at least $\mathbf{4 8}$ hours. Blocks of tissue were then washed in running tap water for $\mathbf{2 4}$ hours followed by immersion in gum sucrose for a further 24 hours before being frozen on to a cryostat chuck in a dry ice and acetone slush. Sections were cut at $7 \mu$ and mounted directly on to gelatinized slides. Duplicate sections extracted in acetone at room temperature for 60 minutes and then washed in 


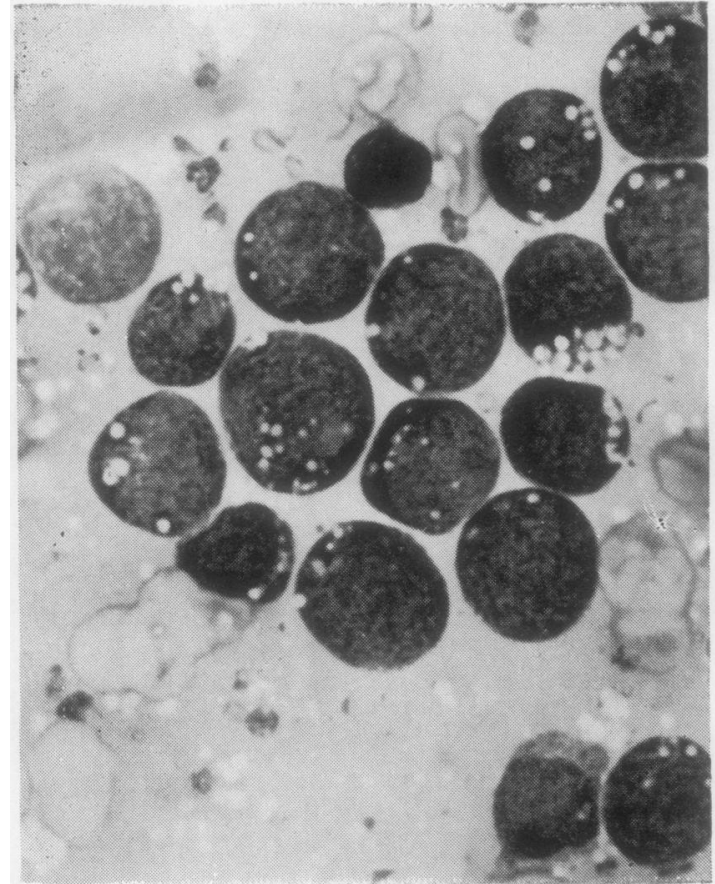

FIG. 1.

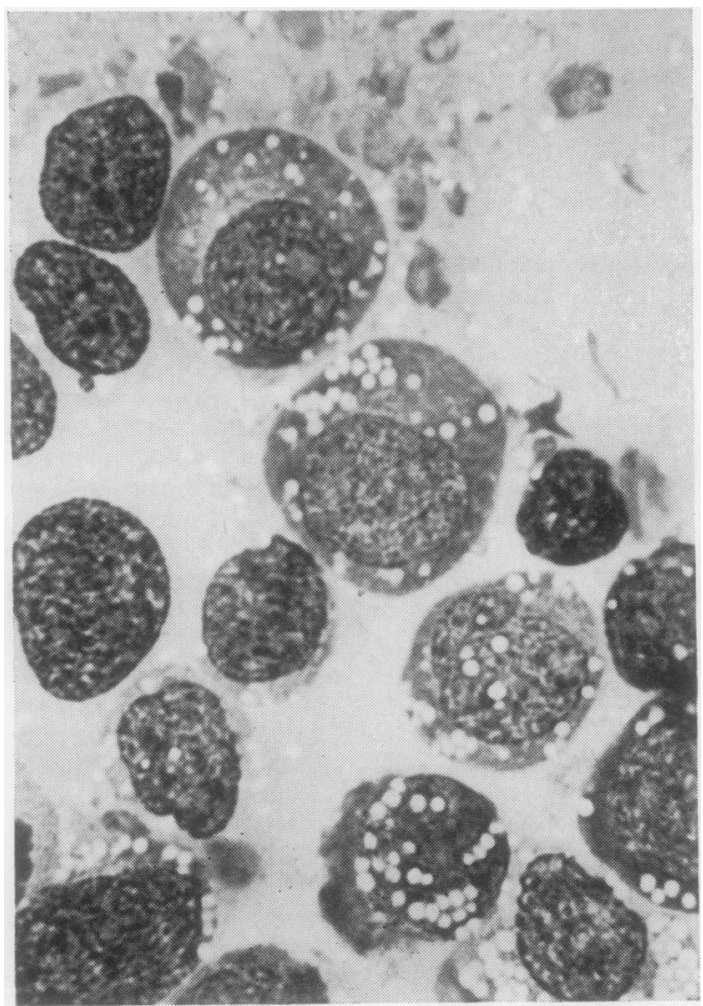

FIG. 3.

FIGS. 1-4. Sections stained with May Grunwald Giemsa stain.

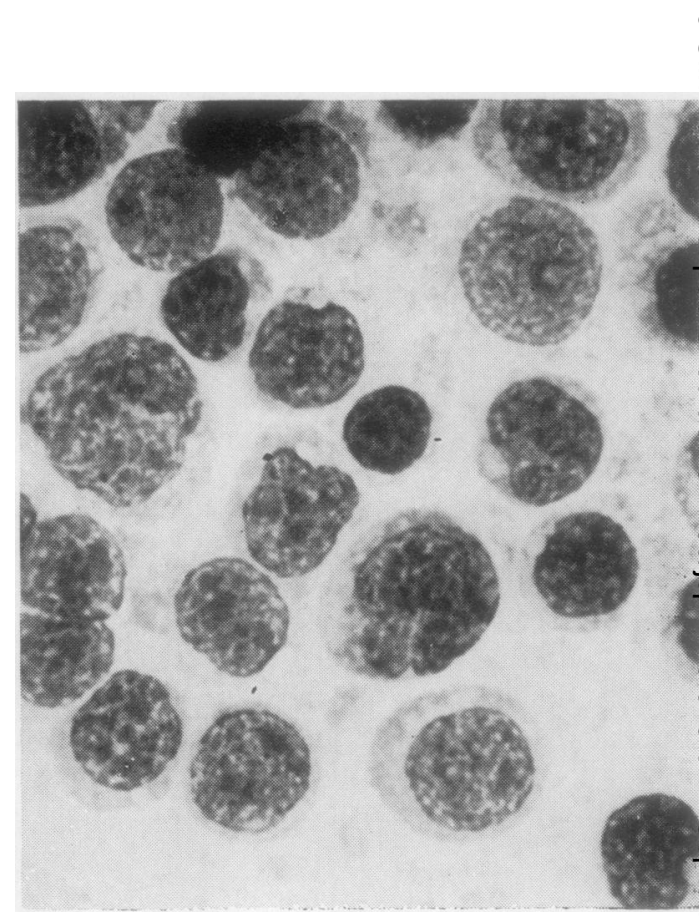

FIG. 2.

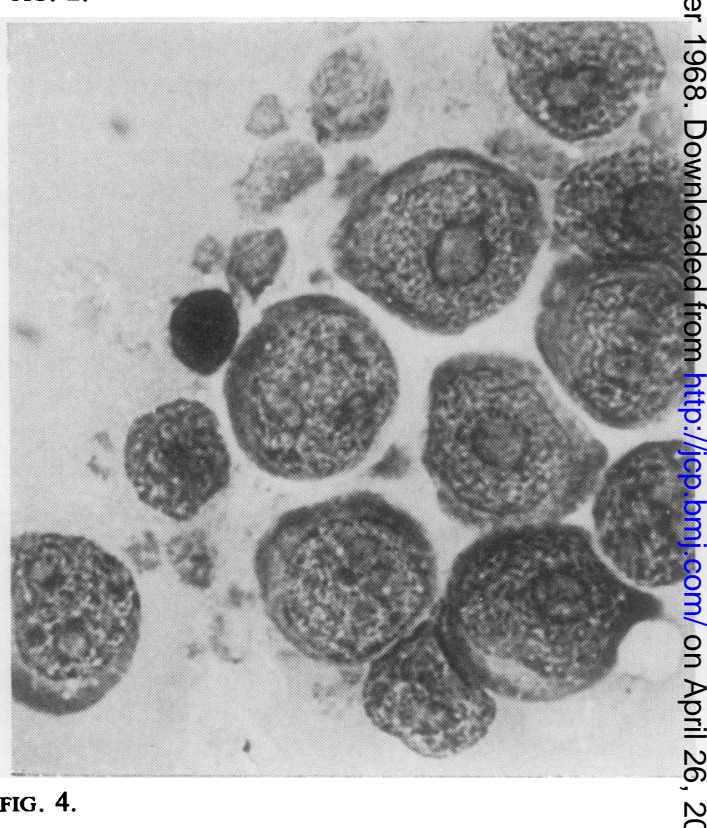

FIG. 1. Imprint of Burkitt's tumour showing the charaet teristic coarse cytoplasmic vacuolation. $\times 2,811$

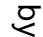

FIG. 2. Imprint of lymphocytic lymphoma, poorly differe tiated. $\times 2,811$.

FIG. 3. Imprint of histiocytic lymphoma showing marked vacuolation of cells. $\times 2,811$.

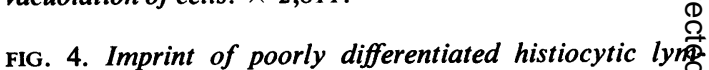
phoma (stem cell lymphoma) showing occasional fing cytoplasmic vacuoles. $\times 2,811$. 
TABLE I

DISTRIBUTION OF THE CASES BY AGE

\begin{tabular}{|c|c|c|c|c|}
\hline \multirow{2}{*}{$\begin{array}{l}\text { Age in } \\
\text { Years }\end{array}$} & \multicolumn{4}{|c|}{ Histological Classification } \\
\hline & $\begin{array}{l}\text { Burkitt's } \\
\text { Tumour }\end{array}$ & $\begin{array}{l}\text { Lymphocytic } \\
\text { Lymphoma }\end{array}$ & $\begin{array}{l}\text { Histiocyticl } \\
\text { Stem-cell } \\
\text { Lymphoma }\end{array}$ & $\begin{array}{l}\text { Hodgkin's } \\
\text { Disease }\end{array}$ \\
\hline $0-5$ & 9 & 2 & - & - \\
\hline $6-10$ & 29 & 2 & 3 & 5 \\
\hline $11-15$ & 13 & 1 & 2 & - \\
\hline $16-20$ & 3 & - & 3 & 2 \\
\hline $21-25$ & - & 1 & - & 1 \\
\hline $26-30$ & 1 & 4 & 1 & 2 \\
\hline $31-35$ & - & 1 & 1 & - \\
\hline $36-40$ & - & 3 & 3 & 3 \\
\hline $41-45$ & - & 2 & 3 & - \\
\hline $46-50$ & - & 7 & 7 & - \\
\hline $51-55$ & - & 1 & 4 & - \\
\hline $56-60$ & - & 2 & 2 & 2 \\
\hline $60+$ & - & 1 & 5 & 3 \\
\hline Adult ${ }^{1}$ & - & 1 & 6 & 1 \\
\hline Total cases & 55 & 28 & 40 & 19 \\
\hline
\end{tabular}

'Cases recorded as adult were those cases from 'up country' hospitals in which 'adult' had been recorded on the biopsy form but the patient's exact age had not been stated.

TABLE II

SITE OF BIOPSY OF THE CASES

Biopsy Site

Histological Classification

\begin{tabular}{llll}
\hline $\begin{array}{l}\text { Burkitt's } \\
\text { Tumour }\end{array}$ & $\begin{array}{l}\text { Lymphocytic } \\
\text { Lymphoma }\end{array}$ & $\begin{array}{l}\text { Histiocyticl } \\
\text { Stem-cell } \\
\text { Lymphoma }\end{array}$ & $\begin{array}{l}\text { Hodgkin's } \\
\text { Disease }\end{array}$ \\
\hline
\end{tabular}

7

24

26

17

Superficial

lymph nodes
Abdominal lymph nodes

and retroperitoneum

Jaw/orbit

Other bones

Gastrointestinal tract

Omentum/mesentery

Liver

Spleen

Kidneys

Bladder

Ovary

Testis

Thyroid

Breast

Subcutaneous tissue

Necropsy

\begin{tabular}{r}
7 \\
3 \\
14 \\
4 \\
\hline 4 \\
2 \\
\hline 3 \\
\hline 7 \\
1 \\
1 \\
1 \\
3 \\
5
\end{tabular}

Total

\begin{tabular}{rr}
3 & 1 \\
14 & - \\
\hline 4 & -1 \\
2 & - \\
\hline 3 & - \\
\hline 7 & - \\
1 & - \\
1 & - \\
1 & - \\
3 & - \\
5 & 2 \\
55 & -
\end{tabular}

distilled water before staining served as controls. Lillie and Ashburn's iso-propanol oil red 0 method (Culling, 1963) with haematoxylin as a counterstain was used to demonstrate neutral fat. Sudan black B staining was performed, using a saturated solution of the dye in $70 \%$ isopropyl alcohol with differentiation in $70 \%$ isopropyl alcohol followed by Mayer's carmalum as a counterstain (Culling, 1963).

\section{RESULTS}

The age distribution of the cases in this study is shown in Table I. The preponderance of cases of Burkitt's tumour in childhood and adolescence is 


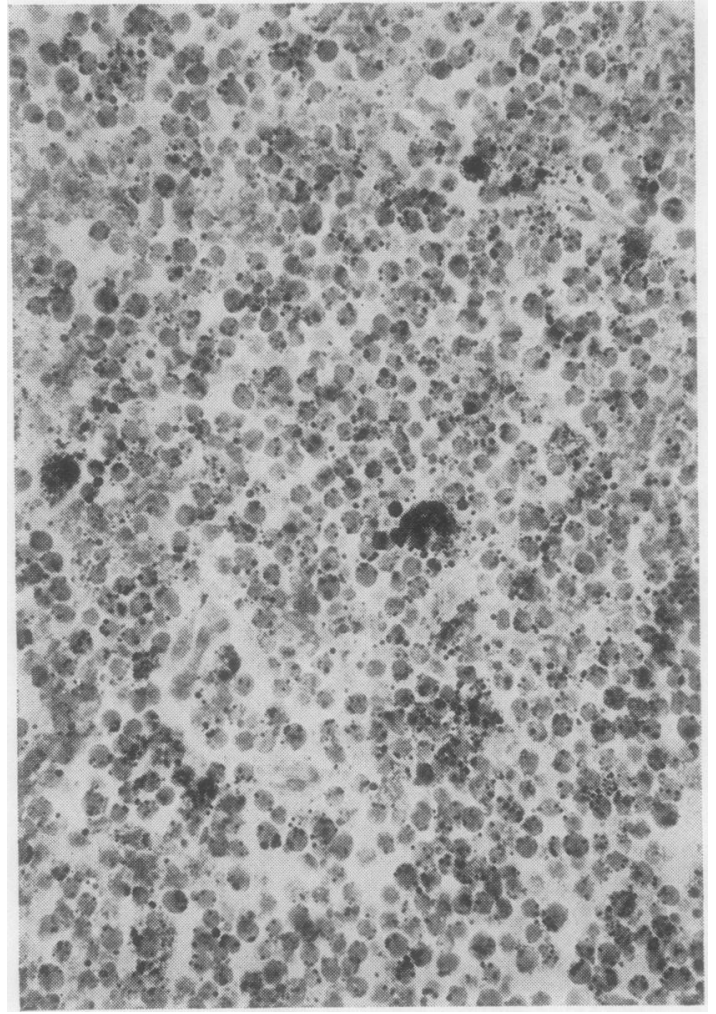

FIG. 5.

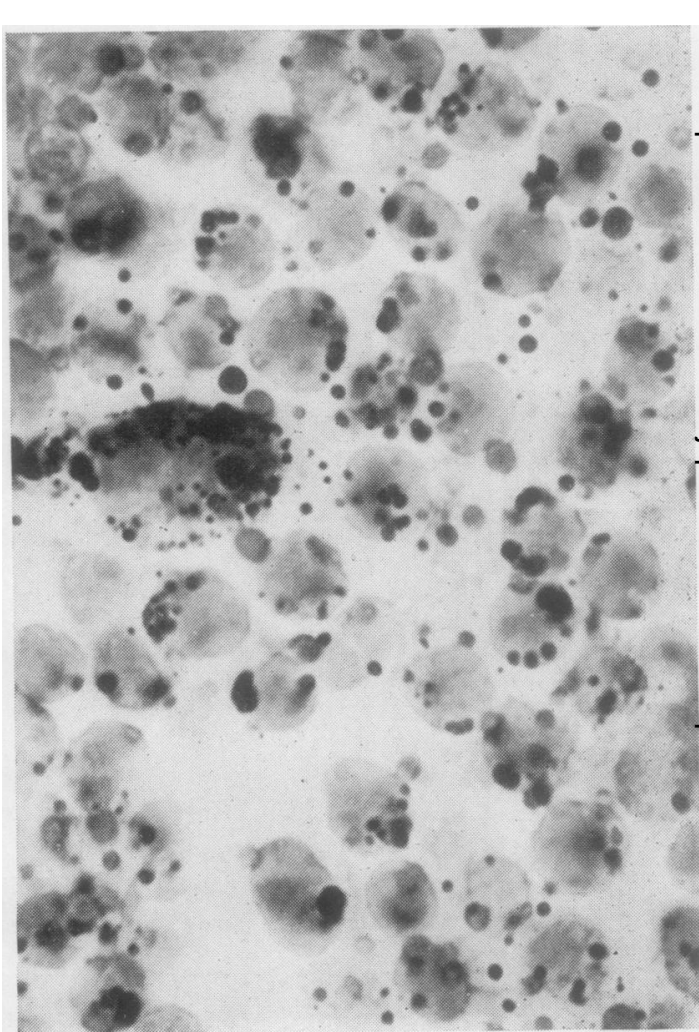

FIG. 6 .

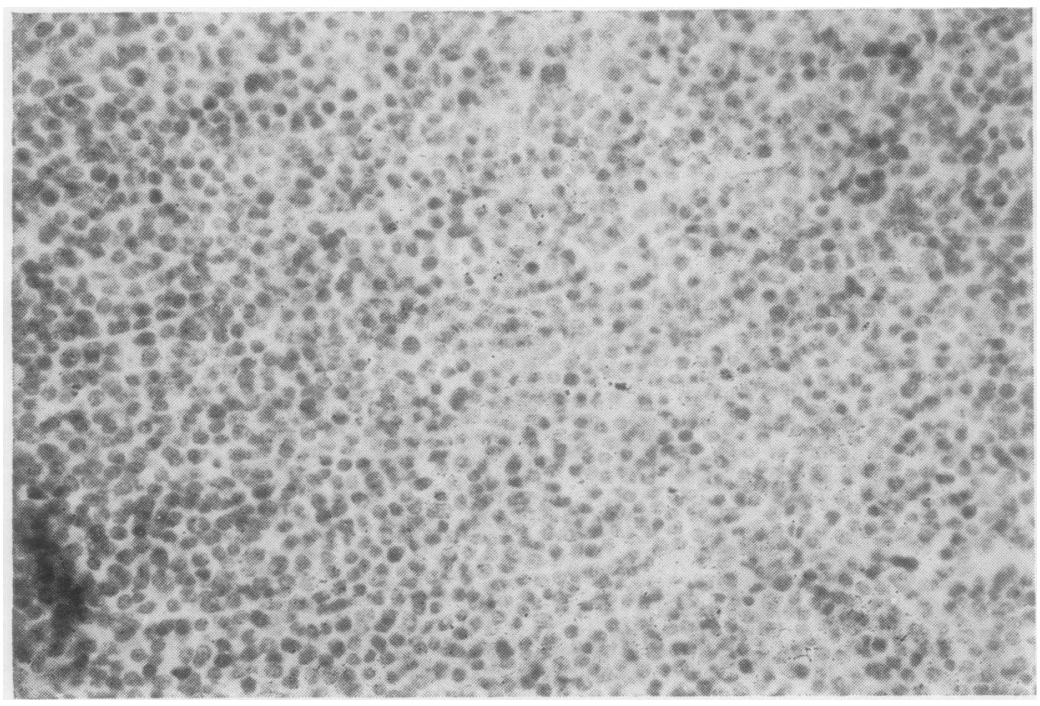

FIG. 7.

FIGS. 5-11. Sections were stained with oil red 0 and haematoxylin.
FIG. 5. Section of Burkitt's tumour showing abundant coarse fat droplets in lymphoid cells and nonneoplastic histiocytes. $\times 702.8$

FIG. 6. Section of Burkitt's 음 tumour showing coarse fat droplets in cytoplasm of lymphoid cells and nonneoplastic histiocytes. $\times 2,81 \mathrm{~N}$

FIG. 7. Section of lymphocytio lymphoma showing almost complete absence of fat droplets. $\times 702$.

N 


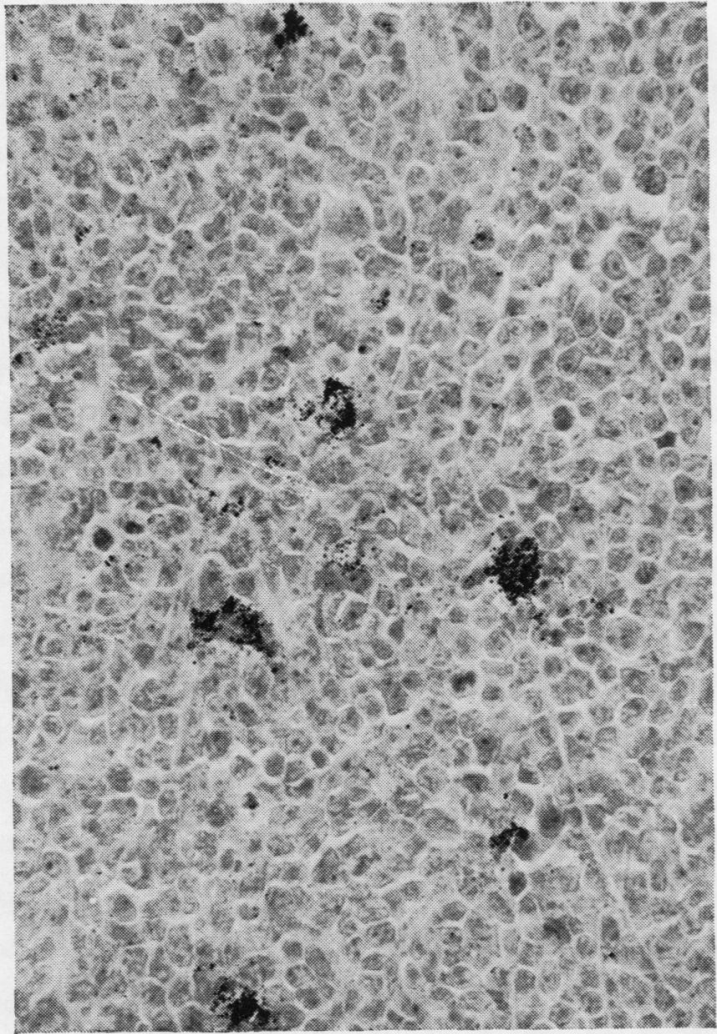

FIG. 8.

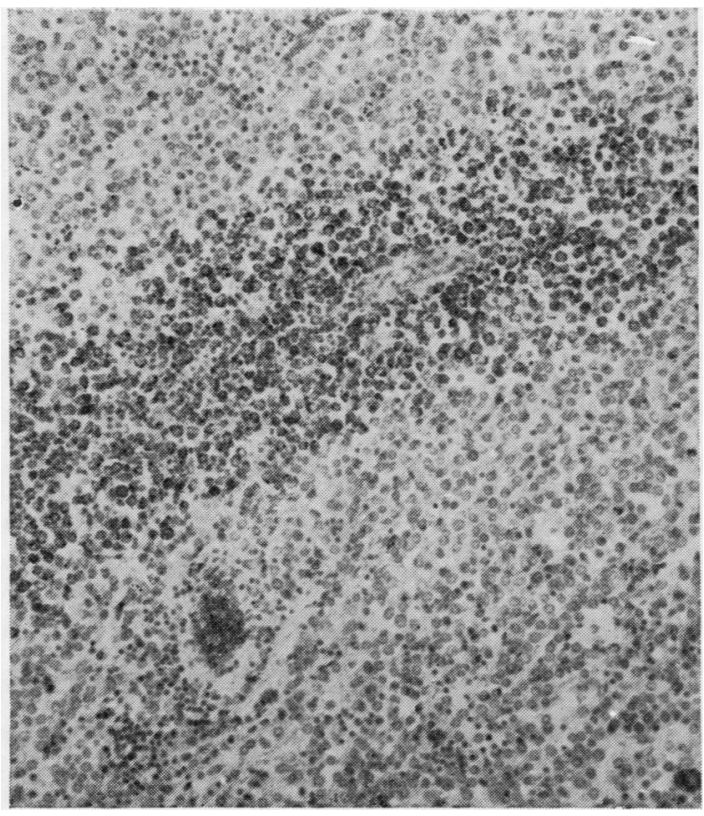

FIG. 9.

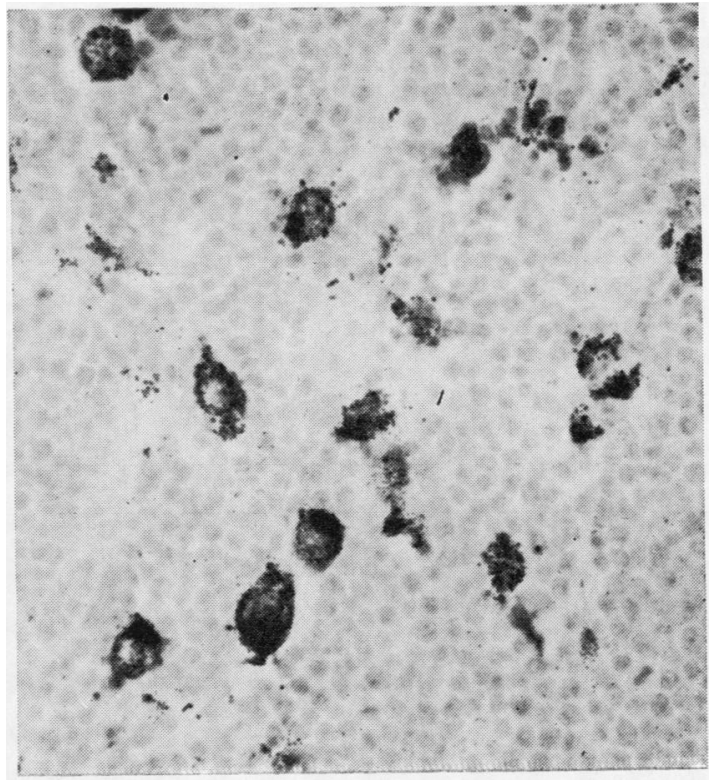

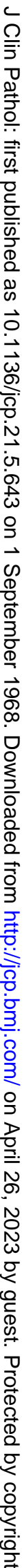

FIG. 11.

FIG. 8. Histiocytic lymphoma showing lipid droplets in occasional cells only. $\times 702$.

FIG. 9. Histiocytic lymphoma showing patchy distribution of lipid droplets in tumour cells. $\times 279$.

FIG. 10. Lymphocytic lymphoma showing abundant lipid in non-neoplastic histiocytes but none in lymphoid cells. $\times 702$.

FIG. 11. Hodgkin's granuloma showing lipid droplets in malignant histiocytes and Sternberg Reed cells. $\times 702$. 
TABLE III

LIPID CONTENT OF MALIGNANT LYMPHOMAS BASED ON OIL RED 0 STAINING

\begin{tabular}{|c|c|c|c|}
\hline & $\begin{array}{l}\text { Burkitt's } \\
\text { Tumour }\end{array}$ & $\begin{array}{l}\text { Lymphocytic } \\
\text { Lymphoma }\end{array}$ & $\begin{array}{l}\text { Histiocytic/ } \\
\text { Lymphoma }\end{array}$ \\
\hline \multicolumn{4}{|c|}{$\begin{array}{l}\text { Percentage of tumour cells } \\
\text { containing fat droplets }\end{array}$} \\
\hline $0-5$ & 2 & 22 & 11 \\
\hline $5-20$ & 4 & 3 & 13 \\
\hline $20-50$ & 2 & 2 & 6 \\
\hline $50+$ & 47 & $\overline{1}$ & 10 \\
\hline \multicolumn{4}{|c|}{ Quality of fat droplets } \\
\hline Fine & 2 & 11 & 13 \\
\hline Medium & 6 & 3 & 14 \\
\hline Coarse & 47 & $\mathbf{0}$ & 7 \\
\hline \multicolumn{4}{|c|}{$\begin{array}{l}\text { Presence of lipid-containing } \\
\text { non-neoplastic histiocytes in the } \\
\text { biopsy }\end{array}$} \\
\hline None & 2 & 20 & 32 \\
\hline Few & 4 & 7 & 4 \\
\hline Many & 49 & 1 & 4 \\
\hline
\end{tabular}

tation of the results has been obtained by assessing the percentage of cells in the section containing lipid droplets. In $85 \%$ of the biopsies from cases of Burkitt's tumour half or more of the cells contained lipid droplets. These usually numbered from one to 10 per cell and were relatively coarse, ie, between 0.5 and $1.0 \mu$ in diameter (Figs. 5 and 6). In marked contrast the majority of lymphocytic lymphomas were devoid of fat droplets and when droplets were present they were usually very fine in quality (Fig. 7). Histiocytic and stem-cell lymphomas were intermediate between these two groups with almost equal numbers of biopsies showing many lipid droplets as there were with minimal or no lipid (Figs. 8 and 9). Often the amount of lipid varied markedly between different areas of the biopsy in contrast to Burkitt's tumour in which it was mainly uniform throughout (Fig. 9).

The large foamy non-neoplastic histiocytes that give the characteristic 'starry sky' pattern to sections of Burkitt's tumour were usually laden with coarse fat droplets and present in abundance in the sections studied. The fat in these cells was presumably derived from ingested lymphoid cells. Few lymphocytic or histiocytic lymphomas showed the same abundance of lipid-laden histiocytes as Burkitt's tumour (Fig. 10).

Table III does not include the results of Hodgkin's disease because of the difficulty of quantitating the results in this neoplasm. In six of the 19 cases, lipid droplets were seen in the Sternberg Reed cells and in all cases at least some of the malignant histiocytes contained oil red 0 positive droplets (Fig. 11).

Sudan black staining added little to this study. In some instances the lipid droplets revealed by oil red 0 staining were also demonstrated by the Sudan black staining but often the technique resulted in extraction of the neutral fat giving a negative or $\bar{\Phi}$ patchy result. Following acetone extraction of the section there was weak diffuse sudanophilia of the $\stackrel{\mathbb{D}}{3}$ cytoplasm of the non-neoplastic histiocytes in Burkitt's tumour and some of the neoplastic histiocytes of histiocytic lymphomas with this stain. It also highlighted the presence of polymorphs, particularly. in cases of Hodgkin's granuloma.

\section{DISCUSSION}

The results of this study show that in frozen sections ${ }_{\triangle}^{\mathbb{D}}$ of formalin-fixed tissue from cases of Burkitt's $\vec{F}$ tumour it is possible to demonstrate the lipid 3 droplets that form such a characteristic feature of the imprint preparations of this tumour. In contrasto to the abundance of lipid in most Burkitt tumour biopsies the majority of lymphocytic lymphomaso contain little sudanophilic material. Histiocytic and윽 stem-cell lymphomas are almost equally divided between those that contain abundant lipid dropletso and those with little or no stainable lipid. It should also be noted that Hayhoe, Quaglino, and Dollo (1964) found vacuolation of $10 \%$ or more of the cells of 29 out of 140 cases of acute leukaemia, although it is not clear in how many of these the N vacuoles were due to lipid droplets. Cytoplasmic vacuolation may be associated with periodic-acidSchiff-positive material in some leukaemic cells.

Oil red 0 staining of frozen sections may, under certain circumstances, assist in the histological diage nosis of Burkitt's tumour. The presence of vacuolesథ్ల in the cytoplasm of cells in paraffin sections is one ${ }^{\text {? }}$ of the histological features of Burkitt's tumour ${ }^{\circ}$ (Wright, 1967). However, even when cytoplasmic vacuoles are abundant in imprint preparations they? may be difficult to find in the corresponding cells 
in paraffin sections, and if the cytoplasmic preservation has not been good, due to autolysis or poor fixation, they may not be apparent. Under these circumstances, lipid staining may be of particular value since the lipid droplets persist even in autolysed tissue.

It is apparent that the presence of abundant coarse lipid droplets in a lymphoma is not in itself diagnostic of Burkitt's tumour nor yet does the absence of lipid droplets completely exclude the diagnosis of Burkitt's tumour. The significance of abundant lipid droplets in lymphoma cells is similar to that of marked cytoplasmic pyroninophilia (Wright and McAlpine, 1966) in that both are valuable adjuncts to the histological assessment of a malignant lymphoma though neither are in themselves diagnostic.

The histogenesis of the Burkitt tumour cell is still in dispute, mainly because of its primitive nature and lack of differentiation. The presence of lipid droplets in the cells might indicate phagocytic activity, suggesting differentiation towards histiocytes. However, Burkitt tumour cells differ cytologically from the cells of histiocytic lymphomas and the presence of fat droplets in the cells is independent of whether the tumour is infiltrating fat or not. It should also be noted that there are no abnormalities of the serum lipids in children with Burkitt's tumour. In a study of 25 children with Burkitt's tumour and 25 age- and sex-matched controls, the serum cholesterol, free fatty acids, and triglycerides were the same in both groups (Shaper, personal communication).

Apffel and Baker (1964) noted that, although lipid droplets may occasionally be found in the cytoplasm of the normal cells, they are markedly increased in numbers in malignant cells, both from animal and human sources. They suggest that the droplets originate from changes within the cell and are not due to phagocytosis. Changes in the equilibrium of colloid suspensions of lipid within the cells or changes in the tumour cell surface are possible factors leading to the development of lipid droplets. Metabolic changes associated with the very high proliferation rate of Burkitt's tumour (Cooper, Frank, and Wright, 1966) might be responsible for the particularly marked lipid droplet formation in this tumour. The frequency of lipid droplets in biopsies of Burkitt's tumour, their relative uniformity throughout the tumour, and their presence in cells during mitotic activity indicate that they are not a simple degenerative phenomenon.

I am indebted to Mrs E. Buxton for technical assistance. This investigation was supported by a grant from the British Empire Cancer Campaign.

\section{REFERENCES}

Apffel, C. A., and Baker, J. R. (1964). Cancer (Philad.), 17, 176.

Cooper, E. H., Frank, G. L. and Wright, D. H. (1966). Europ. J. Cancer, 2, 377.

Culling, C. F. A. (1963). Handbook of Histopathological Techniques, 2nd ed. Butterworths, London.

Hayhoe, F. G. J., Quaglino, D., and Doll, R. (1964). The cytology and cytochemistry of acute leukaemias. Spec. Rep. Ser. med. Res. Coun. (Lond.), 304.

Wright, D. H. (1963). Brit. J. Cancer, 17, 50.

(1967). In Treatment of Burkitt's Tumour, edited by J. H. Burchenal and D. P. Burkitt, p. 14. (U.I.C.C. Monograph Series, Vol. 8). Springer, Berlin.

_, and McAlpine, J. C. (1966). J. clin. Path., 19, 257. 